\title{
Study on the Consciousness of Husserl's Intentionality Under the Influence of Psychology
}

\author{
Zhongxiu Liu ${ }^{*}$, Junlin $\mathrm{Xu}^{1}$ and Shawn P. Daly ${ }^{2}$ \\ ${ }^{1}$ Foreign Language College, Hunan University of Technology and Business \\ No. 569, Yuelu Avenue, Hunan, China \\ ${ }^{2}$ College of Business, Niagara University, sdaly@niagara.edu, +1 7162868179 \\ Bisgrove Hall, Room 179, Niagara University, NY 14109-2201, USA \\ *Corresponding author details: Zhongxiu Liu; Zhongxiu1005@stu.hutb.edu.cn
}

\begin{abstract}
Husserl accepted the influence of descriptive psychology, inherited and developed the concept of intentionality, criticized and innovated the problem of empiricism from epistemology, and Conscious Intentionality has become the core idea of Husserl's phenomenology. By analyzing Husserl's concept of consciousness, we can clarify the internal structure of Husserl's definition of "consciousness" on the basis of understanding the internal relationship of Husserl's concept of consciousness: the concept of consciousness is not equivalent to the concept of intentionality, only when the concept of consciousness based on intentionality does the real concept of Husserl's consciousness become manifest. Husserl's concept of consciousness not only affects Martin Heidegger and Searle, but also has an important influence on the later philosophy of mind, and promotes the integration of philosophy of mind and philosophy of language.
\end{abstract}

Keywords: descriptive psychology; Husserl; intentionality; consciousness

\section{INTRODUCTION \\ Background of Descriptive Psychology's \\ Influence}

German philosophy in the late 19th century moved gradually away from its pure theoretical nature. To change the dire situation of German philosophy, Brentano proposed to combine philosophy and natural science closely to construct a "philosophy of strict science", and "psychology is a kind of science that can control other sciences and makes them subordinate to themselves" (Brentano 1973), which is that only science can provide correct answers to philosophical questions. Thus, to obtain new developments, German philosophy must be based on psychology.

After examining the traditional philosophical psychology and the experimental psychology represented by Wundt, he pointed out that the traditional philosophical psychology was based on philosophical speculation rather than scientific demonstration, which was vague, metaphysical, mysterious, and lacked "scientific". Experimental psychology, on the basis of considering human beings as the unity of physiology and psychology, often explains psychological phenomena with physiological laws, and only mechanically applies the methods of natural science. This method does not touch the pure psychology because it adds the arbitrariness of physics to the investigation of psychology, but it contains non-psychological impurities (Wang 1997). In his opinion, the traditional philosophical psychology and the experimental psychology represented by Wundt cannot meet the requirements of constructing "strict scientific philosophy".
Therefore, it is necessary to establish a new psychology. Brentano abandoned the mental-physical or physiologicalmental thinking model and turned to the "unique thing" of psychological experience, the "pure psychology" revealed in experience, which was his subject of psychological research.

In 1874, Brentano published Psychology from the standpoint of experience, marking the birth of descriptive psychology. Brentano (1874) borrows the term "intentionality", proposed by the medieval philosophers, to describe the characteristics of psychological phenomena. At the same time, he also gives the concept of "intentionality" richer and profound connotation. In Brentano's view, the so-called "intentionality" of psychological phenomena is essentially a "intentional relationship". The concept of "intentionality" put forward by Brentano has a very important impact on Husserl. Husserl highly evaluates the division of psychological phenomena and physical phenomena from "intentionality" and the in-depth analysis of the composition of psychological phenomena from "intentional relationship" But Husserl believes that Brentano's descriptive psychology is still empiricism, and "philosophy of strict science" should be a doctrine beyond empirical science. It must meet two basic conditions: the first one is absolutely indisputable; Second, the whole content is based on the final proof that it is established by itself and thus completely responsible to itself. The goal of Husserl's phenomenology is to construct the philosophy of strict science on the basis of an absolutely unassailable self-evident. 
Of course, the creation of phenomenology does not mean the complete "break" between Husserl and Brentano. On the contrary, in Husserl's phenomenology, we can clearly see the traces of Brentano's descriptive psychology.

\section{LITERATURE REVIEW}

\section{Origin of Intentionality Theory}

As for the theory of intentionality, it can be traced back to the medieval philosophy of the academy from the etymology. The word "intentionality" originates from the Latin word "intentio", which refers to the activity of shooting an arrow at a target, and thus implies the meaning of "directionality". In medieval literature, the terms "intentio" and "intentional" were frequently used to distinguish between "intentional existence" and "actual existence". In Thomas' philosophy, "intentio" means not only a certain will behavior, but also a certain existence style of the object of consciousness, which is used to distinguish from the existence style of the actual object. In Thomas' view, cognition is to incorporate form into consciousness in a non-material form. Form does not exist in reason and perception, but exists as intention. In short, Thomas's view is based on the ontological and epistemological standpoint of conceptual realism, and regards "intentionality" as the intermediary between internal consciousness and external real object. On the one hand, Thomas explained the existence of intentional objects in consciousness from the perspective of moderate realism; On the other hand, based on Aristotle's abstract theory, he clarified the whole process of rational soul grasping the external real object with the explanation of the relationship between the external real object and the intentional object.

From the perspective of the evolution of the relevant ideological content, we can know that since the ideological content of the "intentionality" theory is closely related to the ideological content of transcendental subjectivity, and from the perspective of the subjectivity thought of traditional philosophical epistemology, ancient Greek philosophy has touched the problem of intentionality more broadly. In Cladillo, Plato touched upon the issue of intentionality by means of speculation and metaphor. Plato pointed out in the tone of Socrates: "Opinion is either from the pursuit, indicating the progress of the soul in the pursuit of knowledge, or from the launch of the bow. The latter explanation is more likely, and thinking about this word can confirm this point. This word is just movement, which applies the movement of the soul to the essence of everything." If the core viewpoints of the above citations are analyzed and compared with the more mature intentionality theory in psychology or phenomenology in the future, it can be seen that there is a certain similarity in form between the two. They all express the meaning of 'consciousness pointing to objects in a way similar to archery'. Of course, we can't think Plato has clearly discussed the theory of intentionality here, but only from the perspective of metaphysical epistemology on the subjectivity and initiative of cognition, which contains a broad guess or association of intentionality itself. In Tyatide, Plato once again touched upon "intentionality" when asking how non-existent things could be considered by us, and Socrates referred to the mechanism of conscious activity when debating "non-existent things" with the Tyatdians, saying that "memory is about something".

This is similar to Husserl's idea that the primary feature of "intentionality' consciousness is always about something", but it still cannot be regarded as intrinsically related to the later mature intentionality theory.

Descartes' “Cogito” Theory

Descartes introduced me from my thinking, and in the mind before thinking has been potentially identified what kind of thinking is the real thinking, and this thinking in Descartes' view is rational (Huang 2019). Descartes (1641) said: "I deem thinking is an attribute of me, only which cannot be separated from me... How long did I think, how long will it be, if I stop thinking, perhaps I will stop the existence... Strictly speaking, I am just a thinking thing, that is, a spirit, a reason, or a reason. Husserl pointed out that although Descartes found the absolute field of 'selfthinking' or self-consciousness, he ignored the intentional structure of 'self-thinking' and regarded it as a spiritual entity relative to "object", thus falling into the fallacy of "naturalism" (Wu 2017).

\section{Locke's Psychologism}

Locke's intuitive classification of experience can be divided into two categories. One is the intuitive perception of external things, and the other is the intuitive perception of internal things, namely, external experience and internal experience. Locke created psychologism as transcendental philosophy through the psychology of inner experience. In Locke's view, things are the general concepts formed by simple concepts. The phenomena and concepts of these things are carried out in continuous reorganization or recombination (Li 2019). In First philosophy, Husserl spoke of "all modern psychology simply noticing pure internal giving and different species and genera, and then scientifically establishing these descriptive concepts, but this description and establishment are not real." Husserl criticized Locke's psychological analysis. He suggested that it should be intentional complex analysis, rather than a simple corresponding concept, and then the concept of composite (Li 2019).

\section{Brentano's Theory of Psychological Intentionality}

Brentano divides all the world phenomena into physical phenomena and psychological phenomena. Physical phenomena don't matter about true or false, but psychological phenomena are the objects of self-evident perception. The general feature of psychological phenomena is intentionality. Brentano pointed out in the book Psychology from the Perspective of Experience, "The philosophy of the middle ages used the concept of existence in the intention of an object to indicate any psychological phenomenon, and we call it, although the following statement is not without ambiguity, the relevance of a certain content, the directivity of an object [it should not be understood as a certain entity], or an internal object. Every psychological phenomenon contains something as its own internal object in different ways: something is presented in an image, something is affirmed or denied in a judgment, something is loved in love, something is hated in hate, something is longed in desire, and so on" (De Boer 1995). This statement contains two meanings. First, psychological phenomenon contains a certain content, which is precisely defined as intentional, internal or spiritual; Second, the orientation of psychological phenomena to a certain content (Zhang 2001).

"Each psychological phenomenon is characterized by the intentional existence of the objects as the philosophers of the Middle Ages call them, and is characterized by the fact that we are willing to call them associated with content, pointing to objects or internal objects. Therefore, we can define psychological phenomena in this way, that is, they are referred to as phenomena involving objects in their own intentional way" (Brendano 1995). Brendano built the relationship between "intention" and "psychological phenomenon", which contains the features of "intrinsic" and "directional". The fundamental feature of intentionality is that any consciousness is oriented towards its object. The pointed object is not the real object, on the contrary, it is the manifestation of the real object in the mind, which depends on the inner things of the mind and is a kind of 'inner existence'. This means the object that consciousness 
points to can be nothing in reality. The object that consciousness points to is fundamentally different from the object that exists in reality. The object that consciousness points to, whether it is real or virtual, can exist in the mind Husserl criticizes Brentano's theory of intentionality with a strong tendency of psychologism and naturalism, which rejects the objectivism of consciousness subjectivity and still treats the mind as a material with intentional characteristics, rather than as the source of sensory motivation of internal or external senses, and adheres to the dual psychological- physical causality (Chen 2015).

Brentano's theory of intentionality only dwells on the intentionality of consciousness as an external object of consciousness, and considers that they are in a parallel position in the structure of consciousness, and does not reach the object and its content as enriched and constructed by intentionality itself. In this sense, Brentano's theory of intentionality has not yet entered the level of phenomenology.

\section{HUSSERL'S THEORY OF INTENTIONALITY \\ Conscious Intentionality}

Husserl believes that transcendental ego is the "subject" of Conscious intentionality in the sense of pure psychological cognition. Prior reduction suspends the setting of natural attitude, leaving only pure consciousness or transcendental ego. Accordingly, intentionality theory is also oriented to a new dimension. intentionality has shifted from the original focused on the analysis of intentional behavior to the analysis of pure consciousness. Transcendental self is not a physical self, but the subject of pure thinking activities. It is the executor of intentional activities. All conscious activities are launched from the transcendental self, and at the same time, they are aggregated by the transcendental self, and the intentionrelated items are constructed through the intentional activities. In Husserl's view, meaning refers to the intention of consciousness, is the consciousness of the object, is as well as the conceptual grasp of intention.

\section{Intention Analysis}

Husserl first discussed intention analysis in interactive subjectivity from the "original restoration". Husserl called transcendental phenomenology a new Cartesianism, that is, taking "thinking" as the subject, but not egoism. Everyone is the subject, and "interactive subjectivity" comes from it. The original reduction is different from the transcendental reduction to the pure consciousness, but the direct original given thing to the specific self, and the field of the most realistic individual self. This process is actually from the transcendental pure consciousness or the individualization of universal self to further demand process. The method of intentionality analysis is to restore the existence and history through phenomenology, to return from sensory experience to pure phenomenon. But this pure phenomenon refers to pure consciousness, pure thought, or pure subjectivity, with the intention of this subject as the absolute object of philosophy.

\section{Intentional Structure}

Husserl divided the structure of intentionality into "intentional behavior-intentional content-object" structure. Intentional behavior is the conscious activity itself. Intentional content refers to the meaning expressed by intentional behavior, and object refers to the object referred to by intentional behavior through intentional content. Since Husserl's discussion of intentionality in Logic Research starts with expression, Husserl said: "Every expression not only expresses something, but also expresses something: it not only has its meaning, but also has relationship with some objects... ...The expression refers to its object by means of its meaning."
Intentional content is the meaning or meaning of conscious activities. Husserl discussed what meaning is from the perspective of language expression. Expression is a meaningful symbol, but this meaning is not inherent in the symbol itself. The symbol itself is only a physical phenomenon-voice or words, but when it is by virtue of the consciousness of a given meaning behavior, and the meaningless physical phenomenon obtains meaning, it thus becomes the expression.

The non-real part of the intention experience is the intention object. Saying it's 'non-real' means that it is not real, but intentionally exists in the consciousness, which is a kind of 'pointing' relationship between consciousness and its object. Corresponding to the intention function, the intention object also has two aspects: First, the abstract content of the intention behavior stipulation, this is the behavior way namely the first aspect of the intention function related matter; Second, the meaning of intentional behavior, which is related to the second aspect of intention.

\section{CLARIFICATION OF THE RELATIONSHIP BETWEEN CONSCIOUSNESS AND INTENTIONALITY \\ Consciousness Concept}

For the definition of consciousness, Husserl thinks that Locke's concept of consciousness is too narrow, only reflects the limited types of intentional consciousness. Husserl also criticized Berkeley's symbolic "phenomenology". Husserl believes that people must admit that people have limitations when they perceive external things, so it is possible to explain human consciousness with symbols. Wilhelm Wundt tried to explain human consciousness with the concept of unity. Husserl thought that Wundt's concept of unity only explained consciousness with abstract spirit, and did not analyze it from practical activities.

Therefore, his concept of unity was also the concept of consciousness which lacked realistic basis. Husserl thought that there were defects in the previous concept of consciousness, and we should pay more attention to the connotation of the concept of consciousness itself. Husserl believes that the concept of consciousness has three basic meanings: as the phenomenological composition of the whole reality of the experience self, as the consciousness of psychological experience in the unity of the experience flow; As an inner consciousness of one's own psychological experience; As a general term of any kind of "psychological behavior" or "intentional experience", consciousness is the consciousness of intentionality and the consciousness of object. Any conscious object is in the consciousness, and there isn't 'thinking beyond the nature of things. But the manifestation of intentional experience is in the realm of consciousness, and the manifestation of things and the manifestation of things are two things, so what we experience is only the manifestation of ideas, rather than things themselves.

\section{The Difference Between Husserl's Intentionality and Consciousness}

The difference between the concept of consciousness and intentionality is obvious, mainly reflected in three aspects. First, the content experience is different. Husserl's conscious experience is a phenomenological experience, not a general experience. Husserl believes that under the same stimulus, the content of being perceived may not always be the same. From the legacy of the state of mind (Dispositionen) of past experience, the embodiment of consciousness produces a variety of different elements. On the contrary, intentional experience is a holistic behavior. It can be understood through the intentional content we see is the broadest field where we can experience matters. Intentional experience has a dual definition. 
On the one hand, in intentional experience, the intentional object constructs itself through the internal characteristics of each experience. On the other hand, intentional experience is actually a kind of content, which acts as the basis of action, but it is not an action.

Secondly, different ways of connection. Husserl believes that the connection of consciousness is 'internal perception'. If "internal perception" is understood as the main connection of consciousness experience, the visibility of intentionality will be useless. Therefore, the distinction between consciousness and intentionality cannot not involve the experience of object contact. For example, when we describe a straight object, if there is no prescriptive setting, our imagination in the concept of consciousness may be a tree or a pencil. Although incomplete description may exist in description, it is correct in conscious cognition. However, as a way of intentional connection, visibility, it requires that the object must have certain provisions and directivity so that our description will be more three-dimensional and accurate. Although the connection of visibility is unnecessary for our conscious cognition, it plays an important role in intentionality. Because if people attribute the intuition of directivity to something that is not noticed or realized, the uncertain factors in the experience will increase. If people want to make a correct understanding of intentionality, they may possibly ignore the intention and being given.

Again, Husserl believes that there is an internal and sequential relationship between consciousness and intentionality. He thinks consciousness is a state of mind, and intentionality is the orientation of object. He summed up two points: First, in the phenomenon, consciousness is actually existing in any creatures, they do not need a concept, because their language and logic can be reflected in real action. intentionality must rely on emotion, thinking and judgment, which is a feature only human beings have. Second, for the generation of consciousness, it is not necessary to have external contact. If people dream, he is also subconscious. But intentionality is mainly reflected in the "direction", where the "direction" means direction, indicating that it has strong pertinence to external objects. Husserl believes that consciousness exists as a basic psychological representation. From the perceptive activities, consciousness appears first than intentionality. From the content of conceptual definition, consciousness is also more extensive than intentionality.

\section{CONCLUSIONS}

Husserl accepted the influence of descriptive psychology, inherited and developed the concept of intentionality, criticized and innovated the problem of empiricism from epistemology. And intentionality of consciousness becomes the core idea of Husserl's phenomenology. On this basis, this paper clarifies Husserl's consciousness, which is different from the traditional study that regards consciousness as the common feature of all psychological phenomena, from the perspective of integrity or consciousness as the understanding and perception of real things and the perspective of linguistics or logical methods. Husserl found a general concept of consciousness for abstract and concrete phenomena. His theory of consciousness is unique in the history of the development of the concept of consciousness and has a great influence on later generations.

Intentionality, originally used as a demarcation between physical and psychological phenomena in Brentano's psychology and as the essential feature of consciousness in Husserl's phenomenology, has become a mark of existence here in Heidegger. Just as Husserl criticizes and inherits Brentano in the aspect of intentionality theory, at the same time, Husserl's intentionality theory will also have an impact on the subsequent corresponding theory because of its own strength. For example, Heidegger's theory is consistent with Husserl's intentional structure of consciousness. Based on Austin and Grice's "intentional theory", Searle details his intentionality theory and studies the relationship between language and mind. He believes that intentionality is a major feature of human speech act, which reflects the speaker's specific mental state and emphasizes that a language is completing a specific speech act or act, and each act reflects the speaker 's intention and intentionality.

Brentano introduced the concept of intentionality into the field of philosophy at the end of the 19th century. Husserl developed and improved the concept of intentionality. Later, in the process of criticizing and developing Husserl's intentionality, people in different fields promoted the initial integration of linguistics and philosophy. The linguistication of philosophy and the philosophication of linguistics began to emerge. intentionality plays an indispensable and important role in this process. Through the transition, extension and expansion from linguistic intentionality to psychological intentionality, intentionality naturally becomes the intersection of contemporary philosophy of language and philosophy of mind.

As one of the important characteristics of human mind and the essential attribute and core content of human consciousness, intentionality has become the core issue of contemporary philosophy of mind and language research. Grasping and applying the remarkable characteristics of intentionality and extending the theory of intentionality to the study of language phenomena will open up a new research perspective, domain and contribute to the further deepening and expansion of language research to a large extent.

\section{FUNDING}

This work was supported by the Hunan Province Education Scientific Research Project Grant XJT (2019) No.291(724), Social and Science Fund of Hunan Province No. 16WLH07 and Hunan Province education science planning issues No. XJK168YY07.

\section{REFERENCES}

[1] Brentano, Franz (1973). Psychology from an empirical standpoint V.2. Humanities Press.

[2] Chen, Panwen (2015). Exploration on Husserl's theory of intentionality. Doctoral dissertation of Jilin University. In Chinese.

[3] De Boer, Theodore (2012). The Development of Husserl's Thought. Springer Science \& Business Media.

[4] Huang, Shujie (2019). "A study of Husserl's thought of intentionality". Jiangxi Normal University. In Chinese.

[5] Li, Jinhua (2019). “On Husserl's criticism of Locke's theory of ideas". Xiamen University. In Chinese.

[6] Wang, Tiancheng (1997). "The foundation of epistemology and the unity of psychological logic: The significance of Husserl's transformation from phenomenology psychology to transcendental phenomenology". Changbai Journal, 4, 38-41.

[7] Wu, Zengding (2017). "Cogito and its subjectivity-A brief analysis of Husserl's interpretation of Descartes in First philosophy". Philosophical Trends, 3, 69-76. In Chinese.

[8] Zhang, Yunpeng (2001). "An analysis of Husserl's intentionality structure of consciousness". Journal of Weifang University, 1(1), 1-8. 